\title{
Small Improvements in Mechanical Axis Alignment Achieved With MRI versus CT-based Patient-specific Instruments in TKA A Randomized Clinical Trial
}

\author{
Tilman Pfitzner MD, Matthew P. Abdel MD, \\ Philipp von Roth MD, Carsten Perka MD, \\ Hagen Hommel MD
}

Received: 18 December 2013/Accepted: 24 June 2014/Published online: 15 July 2014

(C) The Association of Bone and Joint Surgeons $\mathbb{R} 2014$

\begin{abstract}
Background Patient-specific instrumentation in TKA has the proposed benefits of improving coronal and sagittal alignment and rotation of the components. In contrast, the literature is inconsistent if the use of patient-specific instrumentation improves alignment in comparison to conventional instrumentation. Depending on the manufacturer, patient-specific instrumentation is based on either MRI or CT scans. However, it is unknown whether one patient-specific instrumentation approach is more accurate
\end{abstract}

All ICMJE Conflict of Interest Forms for authors and Clinical Orthopaedics and Related Research ${ }^{\mathbb{B}}$ editors and board members are on file with the publication and can be viewed on request.

Each author certifies that he or she, or a member of his or her immediate family, has no funding or commercial associations (eg, consultancies, stock ownership, equity interest, patent/licensing arrangements, etc) that might pose a conflict of interest in connection with the submitted article.

Clinical Orthopaedics and Related Research ${ }^{\mathbb{R}}$ neither advocates nor endorses the use of any treatment, drug, or device. Readers are encouraged to always seek additional information, including FDA approval status, of any drug or device before clinical use.

Each author certifies that his or her institution approved the human protocol for this investigation, that all investigations were conducted in conformity with ethical principles of research, and that informed consent for participation in the study was obtained.

This work was performed at Hospital Maerkisch Oderland, Section Wriezen, Wriezen, Germany and Center for Musculoskeletal SurgeryOrthopedic Department, Charité-Universitätsmedizin Berlin, Berlin, Germany.

T. Pfitzner, P. von Roth, C. Perka

Center for Musculoskeletal Surgery-Orthopedic Department,

Charité-Universitätsmedizin Berlin, Berlin, Germany

M. P. Abdel ( $\square)$

Department of Orthopedic Surgery, Mayo Clinic, Gonda 14

South, 200 First Street SW, Rochester, MN 55905, USA

e-mail: abdel.matthew@mayo.edu than the other and if there is a potential benefit in terms of reduction of duration of surgery.

Questions/purposes We compared the accuracy of MRIand CT-based patient-specific instrumentation with conventional instrumentation and with each other in TKAs. The three approaches also were compared with respect to validated outcomes scores and duration of surgery.

Methods A randomized clinical trial was conducted in which 90 patients were enrolled and divided into three groups: CT-based, MRI-based patient-specific instrumentation, and conventional instrumentation. The groups were not different regarding age, male/female sex distribution, and BMI. In all groups, coronal and sagittal alignments were measured on postoperative standing long-leg and lateral radiographs. Component rotation was measured on CT scans. Clinical outcomes (Knee Society and WOMAC scores) were evaluated preoperatively and at a mean of 3 months postoperatively and the duration of surgery was analyzed for each patient. MRI- and CT-based patientspecific instrumentation groups were first compared with conventional instrumentation, the patient-specific instrumentation groups were compared with each other, and all three approaches were compared for clinical outcome measures and duration of surgery.

Results Compared with conventional instrumentation MRI- and CT-based patient-specific instrumentation showed higher accuracy regarding the coronal limb axis

H. Hommel

Orthopedic Department, Hospital Märkisch Oderland, Section Wriezen, Wriezen, Germany 
(MRI versus conventional, $1.0^{\circ}\left[\right.$ range, $0^{\circ}-4^{\circ}$ ] versus $4.5^{\circ}$ [range, $0^{\circ}-8^{\circ}$ ], $\mathrm{p}<0.001 ; \mathrm{CT}$ versus conventional, $3.0^{\circ}$ [range, $0^{\circ}-5^{\circ}$ ] versus $4.5^{\circ}$ [range, $0^{\circ}-8^{\circ}$ ], $\mathrm{p}=0.02$ ), femoral rotation (MRI versus conventional, $1.0^{\circ}$ [range, $0^{\circ}-2^{\circ}$ ] versus $4.0^{\circ}$ [range, $1^{\circ}-7^{\circ}$ ], $\mathrm{p}<0.001$; CT versus conventional, $1.0^{\circ}$ [range, $0^{\circ}-2^{\circ}$ ] versus $4.0^{\circ}$ [range, $1^{\circ}-7^{\circ}$, $\mathrm{p}<0.001$ ), and tibial slope (MRI versus conventional, $1.0^{\circ}$ [range, $0^{\circ}-2^{\circ}$ ] versus $3.5^{\circ}$ [range, $1^{\circ}-7^{\circ}$ ], p $<0.001 ; \mathrm{CT}$ versus conventional, $1.0^{\circ}$ [range, $0^{\circ}-2^{\circ}$ ] versus $3.5^{\circ}$ [range, $\left.\left.1^{\circ}-7^{\circ}\right], \mathrm{p}<0.001\right)$, but the differences were small. Furthermore, MRI-based patient-specific instrumentation showed a smaller deviation in the postoperative coronal mechanical limb axis compared with CT-based patientspecific instrumentation (MRI versus CT, $1.0^{\circ}$ [range, $0^{\circ}-4^{\circ}$ ] versus $3.0^{\circ}$ [range, $0^{\circ}-5^{\circ}$ ], $\mathrm{p}=0.03$ ), while there was no difference in femoral rotation or tibial slope. Although there was a significant reduction of the duration of surgery in both patient-specific instrumentation groups in comparison to conventional instrumentation (MRI versus conventional, 58 minutes [range, 53-67 minutes] versus 76 minutes [range, 57-83 minutes], $\mathrm{p}<0.001$; CT versus conventional, 63 minutes [range, 59-69 minutes] versus 76 minutes [range, $57-83$ minutes], $\mathrm{p}<.001$ ), there were no differences in the postoperative Knee Society pain and function and WOMAC scores among the groups.

Conclusions Although this study supports that patientspecific instrumentation increased accuracy compared with conventional instrumentation and that MRI-based patientspecific instrumentation is more accurate compared with CT-based patient-specific instrumentation regarding coronal mechanical limb axis, differences are only subtle and of questionable clinical relevance. Because there are no differences in the long-term clinical outcome or survivorship yet available, the widespread use of this technique cannot be recommended.

Level of Evidence Level I, therapeutic study. See the Instructions to Authors for a complete description of levels of evidence.

\section{Introduction}

Restoration of a neutral mechanical axis is one aspect of a TKA that contributes to increased survivorship [25, 29, 43, 51]. Although some have noted that a neutral postoperative mechanical alignment defined as a dichotomous variable is not predictive of survivorship, the gold standard remains neutral postoperative mechanical alignment [7, 25, 39]. Although ideal sagittal alignment is mostly unknown [32], there is evidence that rotational malalignment should be avoided [4]. Innovations including navigation and patientspecific instrumentation have been introduced to theoretically improve the accuracy of alignment obtained with conventional instrumentation $[11,14,35,40]$. The evaluation of navigation has shown that, although it is possible to improve accuracy in the coronal plane $[12,23,40]$, it is not as effective in improving accuracy of rotation or tibial slope [11, 12, 17, 31].

In contrast, patient-specific instrumentation is reported to improve accuracy in multiple planes owing to three-dimensional planning with either MRI or CT $[1,34]$. The method of image acquisition, and thus preoperative planning, is different between the two techniques, and little has been published regarding whether one technique is more accurate than the other $[8,15]$. While there have been studies comparing patient-specific instrumentation with conventional instrumentation the published results are not consistent and most focus on coronal alignment [2, 10, 14, 27, 35-37]. There are only a few studies looking at sagittal alignment [10, 15, 24, 27, 39] and even fewer looking at rotational alignment [27, 39].

We therefore determined whether (1) MRI- or CT-based patient-specific instrumentation provided greater accuracy of implant positioning compared with conventional instrumentation, (2) there was a difference in accuracy between MRI- and CT-based patient-specific instrumentation, (3) there were any differences in validated clinical outcomes scores (Knee Society and WOMAC), and (4) there were any differences in the duration of the surgery among the three approaches.

\section{Patients and Methods}

A randomized clinical trial was performed in which patients were included if they had a diagnosis of primary osteoarthritis, no previous open knee procedures, an extension deficit less than $20^{\circ}$, and coronal deformity less than $15^{\circ}$. In addition, only patients willing to undergo preoperative CT or MRI and wait 6 weeks for the procedure were included. Patients were excluded if they had any metal near the knee that could have interfered with the imaging. Our institution's ethics committee approved the study, and informed consent was obtained from all patients. One hundred twenty-six patients with end-stage osteoarthritis were offered enrollment in this study. One hundred three met the inclusion criteria. Thirteen of these patients declined waiting 6 weeks for surgery.

All 90 patients (90 knees) undergoing cemented, posterior-stabilized TKAs were randomized to one of three groups: CT-based patient-specific instrumentation ( $\mathrm{n}=30$ ), MRIbased patient-specific instrumentation $(\mathrm{n}=30)$, and conventional instrumentation $(\mathrm{n}=30)$ (Fig. 1). After inclusion no patients were lost to followup, and complete datasets were obtained for all patients. An independent participant (KW) completed the randomization process and sealed envelopes were used. All operations were performed by a senior 


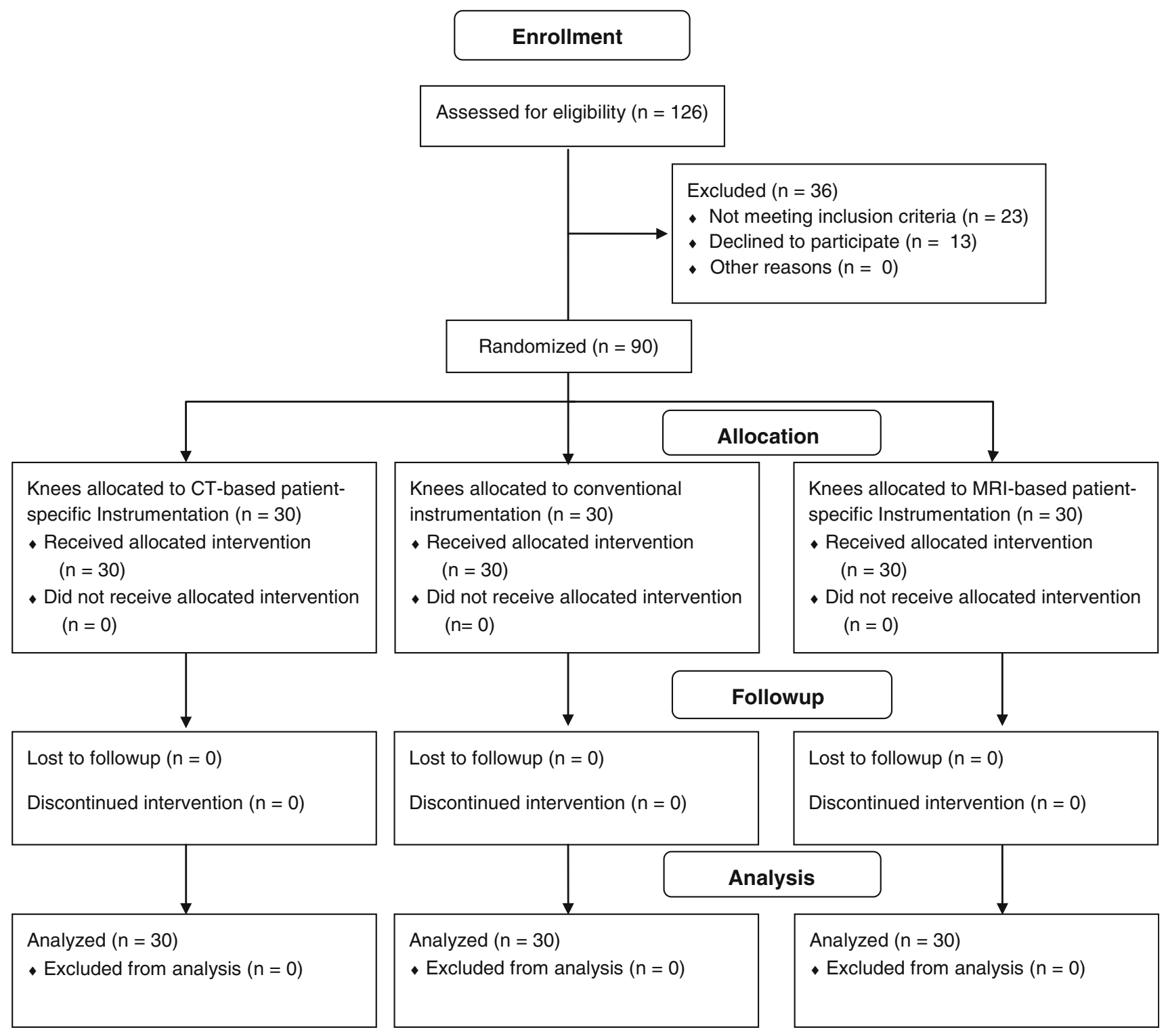

Fig. 1 A flow diagram shows patient enrollment, allocation, followup, and analysis [33].

surgeon $(\mathrm{HH})$ who had completed greater than 1000 primary TKAs and greater than 50 patient-specific instrumentation TKAs.

The study sample comprised 39 men and 51 women, with a mean age of 64 years (range, 54-74 years) and a mean BMI of $30 \mathrm{~kg} / \mathrm{m}^{2}$ (range, $23-35 \mathrm{~kg} / \mathrm{m}^{2}$ ) (Table 1 ). The groups were similar regarding age, sex, and BMI. Mean followup was 3 months (range, 2.3-4.0 months).

Groups and Implants

Thirty CT-based patient-specific cutting blocks were generated (TruMatch ${ }^{\circledR}$; DePuy Orthopaedics, Warsaw, IN,
USA) and used with the intended Sigma ${ }^{\circledR}$ Press Fit Condylar $\left(\mathrm{PFC}^{\mathbb{R}}\right.$ ) High Performance (HP) prosthesis (DePuy) (Table 2). The 30 MRI-based patient-specific cutting blocks were created with the aid of standing long-leg radiographs (Visionaire ${ }^{\mathbb{R}}$; Smith \& Nephew, Inc, Memphis, TN, USA). These blocks were used with the compliant Journey ${ }^{\circledR}$ Bicruciate Substituting (BCS) implant (Smith \& Nephew). The 30 patients who underwent conventional instrumentation received the Journey ${ }^{\circledR}$ BCS system.

To minimize an effect of the specific design in the selected implants, both were similar regarding being a multiradius femoral component, fully cemented, cruciate substituting design with a fixed bearing and without 
Table 1. Patient demographics and clinical outcomes

\begin{tabular}{|c|c|c|c|c|}
\hline Variable & $\begin{array}{l}\text { CT-based patient- } \\
\text { specific instrumentation } \\
\text { group }(\mathrm{n}=30)\end{array}$ & $\begin{array}{l}\text { MRI-based patient- } \\
\text { specific instrumentation } \\
\text { group }(\mathrm{n}=30)\end{array}$ & $\begin{array}{l}\text { Conventional } \\
\text { instrumentation } \\
\text { group }(\mathrm{n}=30)\end{array}$ & $\mathrm{p}$ value \\
\hline Sex (male:female) (number of patients) & $12: 18$ & $14: 16$ & $13: 17$ & 0.87 \\
\hline Age (years)* & $63(54-73)$ & $65(56-74)$ & $64(54-74)$ & 0.11 \\
\hline BMI $\left(\mathrm{kg} / \mathrm{m}^{2}\right)^{*}$ & $30(25-33)$ & $30(25-34)$ & $31(23-35)$ & 0.73 \\
\hline \multicolumn{5}{|l|}{ Knee Society pain score (points)* } \\
\hline Preoperative & $24(9-39)$ & $24(8-32)$ & $26(9-38)$ & 0.06 \\
\hline Postoperative & $90(85-100)$ & $90(87-100)$ & $89(85-100)$ & 0.06 \\
\hline \multicolumn{5}{|l|}{ Knee Society function score (points)* } \\
\hline Preoperative & $18(10-28)$ & $17(10-27)$ & $17(10-28)$ & 0.53 \\
\hline Postoperative & $78(70-100)$ & $81(67-100)$ & $77(67-100)$ & 0.80 \\
\hline \multicolumn{5}{|l|}{ WOMAC score (points)* } \\
\hline Preoperative & $65(53-88)$ & $65(54-87)$ & $63(52-86)$ & 0.41 \\
\hline Postoperative & $24(16-36)$ & $26(17-37)$ & $26(16-36)$ & 0.36 \\
\hline
\end{tabular}

* Values are expressed as median, with range in parentheses.

Table 2. Patient groups

\begin{tabular}{llll}
\hline Variables & $\begin{array}{l}\text { CT-based patient-specific } \\
\text { instrumentation group }(\mathrm{n}=30)\end{array}$ & $\begin{array}{l}\text { MRI-based patient-specific } \\
\text { instrumentation group }(\mathrm{n}=30)\end{array}$ & $\begin{array}{l}\text { Conventional instrumentation } \\
\text { group }(\mathrm{n}=30)\end{array}$ \\
\hline Implant & DePuy Sigma ${ }^{\circledR}$ PFC $^{\circledR}$ & Smith \& Nephew Journey ${ }^{\circledR}$ BCS & Smith \& Nephew Journey ${ }^{\circledR}$ BCS \\
Image acquisition & $\mathrm{CT}$ & MRI and radiographs & Plain radiographs \\
Instrumentation & TruMatch $^{\circledR}$ & Visionaire & Conventional \\
\hline
\end{tabular}

$\mathrm{PFC}^{\mathbb{R}}=$ Press Fit Condylar; BCS = Bicruciate Substituting.

patellar resurfacing. The basic difference was that the Journey BCS design is bicruciate substituting design while the PFC Sigma is a posterior stabilizing design. The duration of surgery was defined as the time between skin incision and end of skin closure and was documented for each patient.

Planning of the implant position in each group was done in the frontal plane perpendicular to the mechanical femoral and tibial axes. In addition, rotation of the femoral component was set parallel to the surgical transepicondylar axis, and the posterior tibial slope was set to $3^{\circ}$, following the manufacturers' implant-specific recommendations. All plans in the patient-specific instrumentation groups were specifically reviewed, modified, and approved by the surgeon before use. In the conventional instrumentation group, planning was performed with digital templating software (Medicad, HECTEC GmbH; Landshut, Germany). If the planned size of the implant had to be changed intraoperatively, this was documented for each patient.

Standard instrumentation was used, with an extramedullary tibial guide and intramedullary femoral rod. The angle between the mechanical and anatomic femoral axes was adapted individually from the planning. In the conventional instrumentation group, preoperative planning and intraoperative resection were done perpendicular to the mechanical femoral and tibial axes.

Other than the different implants and instrumentation, all three groups received the same perioperative course. In particular, patients had a multimodal pain anesthesia regimen that included general anesthesia with peripheral nerve blocks. No tourniquets were used in any surgeries, and all patients received a drain. Venous thromboembolism prophylaxis was provided with low-molecular-weight heparin in all patients. All patients had the identical accelerated rehabilitation program postoperatively.

\section{Radiographic Analysis and Clinical Evaluation}

Preoperative and postoperative radiographs were performed under standardized conditions [13]. The patients were in a standing upright position with their backside to the cassette and with equally distributed weightbearing. The tibial tubercle was positioned straight forward implicating that the sagittal flexion axis was set parallel to the $\mathrm{x}$-ray beam [13]. The $\mathrm{x}$-ray beam was centered to the joint 
line level [52]. Criteria for correct rotation of the radiograph were central patellar tracking, coverage of the fibular head by the tibia $(2 / 3 ; 1 / 3)$, and position of the upper ankle and foot on imaging [20, 42].

Additionally preoperative lateral radiographs were completed for all patients [42]. In the patient-specific instrumentation groups, CT or MRI was completed in accordance with the manufacturers' protocol. Postoperatively, radiographic analysis included a standing long-leg radiograph, a lateral knee radiograph, and a CT scan to measure rotation of the components [3]. All measurements on conventional radiographs were performed with the standard digital picture archiving and communication system used at the institution (Centricity Enterprise ${ }^{\mathrm{TM}}$, Web 3.0, GE Healthcare Pty Ltd, Piscataway, NJ, USA). The following axes were determined: the coronal mechanical limb alignment was measured as an angle between two lines; the line connecting the center of the hip and the knee and the line connecting the center of the knee and the upper ankle. Coronal femoral implant alignment was measured between the mechanical femoral axis and the tangent of the distal femoral condyles. Determination of the coronal tibial implant position was performed by analyzing the angle between the mechanical tibial axis and the tangent at the implant-bone interface of the tibia. Sagittal tibial alignment was measured on long cassette lateral radiographs as the angle between the anterior tibial cortex and the tangent of the implant's inferior surface. The CT scan was used to determine rotational alignment of the femoral component in relation to the surgical transepicondylar axis on axial views. The radiologic measurements (radiographs and CT) were performed by an experienced investigator (TP) blinded to the patients' allocation consistent with a previous report [49].

The clinical outcomes of all patients were recorded in a standardized manner using the Knee Society pain score, Knee Society functional score, and the WOMAC score, preoperatively and at a mean of 3 months (range, 2.3-4.0 months) postoperatively [5, 21].

\section{Statistical Analysis}

To compare the coronal, sagittal, and axial alignment measurements among the three groups, we used a nonparametric approach, as described by others [45, 49]. The actual measurements were obtained for all groups and the deviation from the planned measurement was compared among groups. The data are presented as median and ranges. Significant differences among groups were evaluated by a one way ANOVA (Kruskal-Wallis test) and for comparison of proportions (Fisher's exact test). Dunn's nonparametric comparison was performed for post hoc testing. An a priori power analysis was performed to calculate the sample size. Based on a power of $0.80(1-\beta)$ with $\alpha=0.05$ to detect a difference in deviation from a target of $1^{\circ}$ using a one way ANOVA in three equal groups, a total required sample size of 63 was identified. To account for possible dropouts during the study, a total sample size of 90 was assumed appropriate. We used SPSS $^{\circledR}$ software (Version 19; IBM Corp; Somers, NY, USA) for statistical analyses. The level of significance was set with an alpha of 0.05 .

\section{Results}

\section{Radiographic Differences}

Patients with MRI- and CT-based patient-specific instrumentation showed significantly less deviation in coronal mechanical limb alignment compared with patients with conventional instrumentation, although the differences were small (MRI versus conventional, $1.0^{\circ}$ [range, $0^{\circ}-4^{\circ}$ ] versus $4.5^{\circ}$ [range, $0^{\circ}-8^{\circ}$ ], $\mathrm{p}<0.001$; CT versus conventional, $3.0^{\circ}$ [range, $0^{\circ}-5^{\circ}$ ] versus $4.5^{\circ}$ [range, $0^{\circ}-8^{\circ}$, $\mathrm{p}=0.02$ ) (Fig. 2). Looking at the rate of outliers greater than $3^{\circ}$, patient-specific instrumentation showed fewer outliers in comparison to conventional instrumentation (Table 3). Compared with conventional instrumentation, both patient-specific instrumentation groups showed greater accuracy for the mechanical femoral axis (MRI versus conventional, $1.0^{\circ}$ [range, $0^{\circ}-2.5^{\circ}$ ] versus $2.7^{\circ}$ [range, $1^{\circ}-6^{\circ}$ ], $\mathrm{p}<0.001 ; \mathrm{CT}$ versus conventional, $1.0^{\circ}$ [range, $0^{\circ}-2.5^{\circ}$ ] versus $2.7^{\circ}$ [range, $1^{\circ}-6^{\circ}$ ], $\mathrm{p}<0.001$ ), and mechanical tibial axis (MRI versus conventional, $1.0^{\circ}$ [range, $0^{\circ}-1.5^{\circ}$ ] versus $3.0^{\circ}$ [range, $1^{\circ}-6^{\circ}$ ], $\mathrm{p}<0.001 ; \mathrm{CT}$ versus conventional, $1.0^{\circ}$ [range, $0^{\circ}-2^{\circ}$ ] versus $3.0^{\circ}$ [range, $\left.\left.1^{\circ}-6^{\circ}\right], \mathrm{p}<0.001\right)$.

For the rate of outliers greater than $3^{\circ}$, there was no difference between patient-specific instrumentation and conventional instrumentation for alignment of the femoral component (Table 3). Both patient-specific instrumentation groups showed smaller deviations in postoperative femoral rotation from the surgical transepicondylar axis (MRI versus conventional, $1.0^{\circ}$ [range, $0^{\circ}-2^{\circ}$ ] versus $4.0^{\circ}$ [range, $1^{\circ}-7^{\circ}$ ], $\mathrm{p}<0.001 ; \mathrm{CT}$ versus conventional, $1.0^{\circ}$ [range, $0^{\circ}-2^{\circ}$ ] versus $4.0^{\circ}$ [range, $1^{\circ}-7^{\circ}$ ], $\left.\mathrm{p}<0.001\right)$ and in posterior tibial slope from $3^{\circ}$ compared with conventional instrumentation (MRI versus conventional, $1.0^{\circ}$ [range, $0^{\circ}-2^{\circ}$ ] versus $3.5^{\circ}$ [range, $1^{\circ}-7^{\circ}$ ], $\mathrm{p}<0.001$; CT versus conventional, $1.0^{\circ}$ [range, $0^{\circ}-2^{\circ}$ ] versus $3.5^{\circ}$ [range, $1^{\circ}$ $7^{\circ}$ ], $\mathrm{p}<0.001$ ) (Table 4). Again effect sizes were small. Taking $3^{\circ}$ as a cutoff for femoral rotation, patient-specific instrumentation showed a decrease of outliers whereas there was no difference for tibial slope (Table 3). 


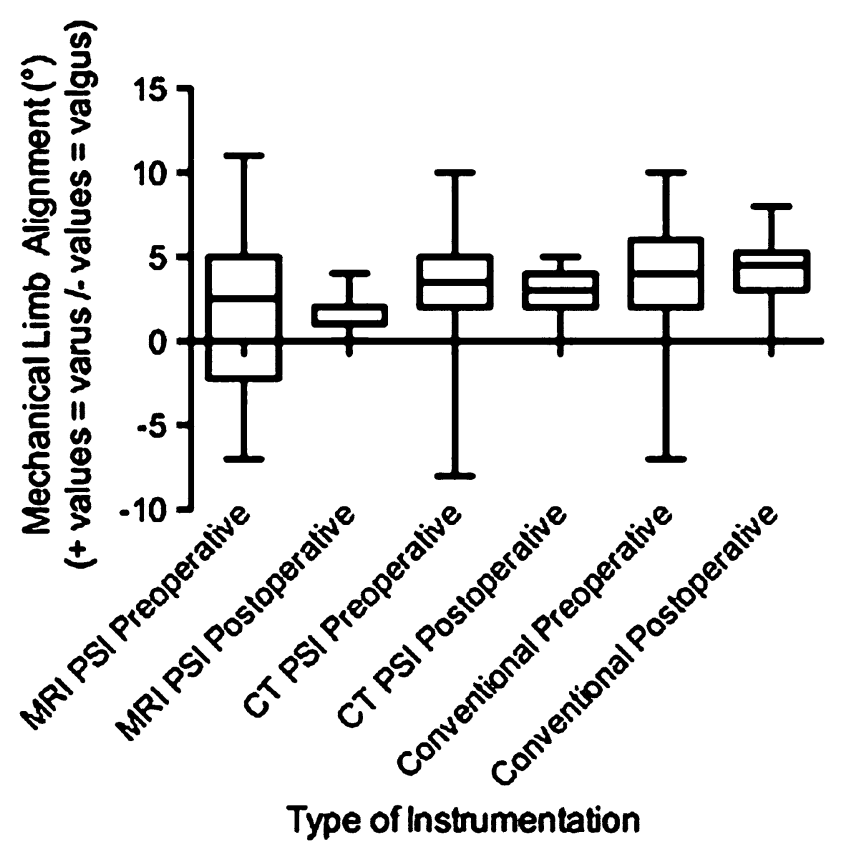

Fig. 2 A boxplot of preoperative and postoperative coronal mechanical limb alignment for the three groups is shown. MRI- and CT-based patient-specific instrumentation had less deviation in overall mechanical alignment compared with conventional instrumentation, but MRIbased patient-specific instrumentation had a smaller deviation than CT-based patient-specific instrumentation. Horizontal line = Median; box $=$ upper and lower quartile; Whisker $=$ Minimum and Maximum. PSI $=$ patient-specific instrumentation.

Radiographic Differences Between MRI- and CT-based Patient-specific Instrumentation

The comparison between patient-specific instrumentation groups for alignment showed only small differences. MRIbased patient-specific instrumentation had a smaller deviation from the plan in postoperative coronal mechanical limb alignment compared with CT-based patient-specific instrumentation (MRI versus CT, $1.0^{\circ}$ [range, $0^{\circ}-4^{\circ}$ ] versus $3.0^{\circ} \quad$ range, $0^{\circ}-5^{\circ}$ ], $\mathrm{p}=0.03$ ) (Table 5), and a decrease in outliers greater than $3^{\circ}$ (MRI versus CT, 2/30 [7\%] versus 9/30 [30\%], odds ratio [OR], 0.16, 95\% CI, $0.03-0.85, \mathrm{p}=0.04)$. The MRI- and CT-based patientspecific instrumentation groups did not differ regarding mechanical femoral or tibial axis. No differences were found between the patient-specific instrumentation groups regarding deviations in postoperative femoral rotation from the surgical transepicondylar axis and in posterior tibial slope from $3^{\circ}$.

\section{Clinical Outcomes}

A comparison of the Knee Society pain, Knee Society function, and WOMAC scores among the groups showed no differences preoperatively or at the mean followup of 3 months postoperatively (Table 1).

\section{Duration of Surgery}

The duration of surgery decreased in both patient-specific instrumentation groups compared with the conventional instrumentation group (MRI versus conventional, $58 \mathrm{~min}$ utes [range, 53-67 minutes] versus 76 minutes [range, 57-83 minutes], $\mathrm{p}<0.001 ; \mathrm{CT}$ versus conventional, 63 minutes [range, 59-69 minutes] versus 76 minutes [range, 57-83 minutes], $\mathrm{p}<0.001)$ and in both patientspecific instrumentation groups (MRI versus CT, 58 minutes [range, 53-67 minutes] versus 63 minutes [range, 59-69 minutes], $\mathrm{p}<0.001)$. The planned size of the implant had to be changed intraoperatively at the femur in $17 \%$ of the MRI-based patient-specific instrumentation group, in $20 \%$ of the CT-based patient-specific instrumentation group, and in $47 \%$ of the conventional instrumentation group. At the tibial component, an intraoperative change of the planned size was necessary in $17 \%$ of MRI-based patient-specific instrumentation, 30\% of CTbased patient-specific instrumentation, and $40 \%$ of conventional instrumentation.

\section{Discussion}

Although some studies have investigated the cost, time, and radiographic parameters associated with the use of patient-specific instrumentation, little attention has been given to the various technologies used to actually acquire the preoperative images $[16,50]$. The goals of the current randomized clinical trial were to determine whether MRIor CT-based patient-specific instrumentation had improved accuracy relative to conventional instrumentation regarding postoperative alignment, there was a difference in accuracy between MRI- and CT-based patient-specific instrumentation, there were any differences in clinical outcomes as judged by Knee Society and WOMAC scores, and duration of surgery with the three approaches. We found that although the alignment was more precise using MRI- and CT-based patient-specific instrumentation compared with conventional instrumentation, the differences were small, not associated with any early postoperative improvements in validated outcomes scores, and likely of little clinical importance. Given that the increased costs of patient-specific instrumentation implants with only slight reduction in duration of surgery and the paucity of data pertaining to the long-term performance of the relatively new implant designs used in this study, we do not believe 


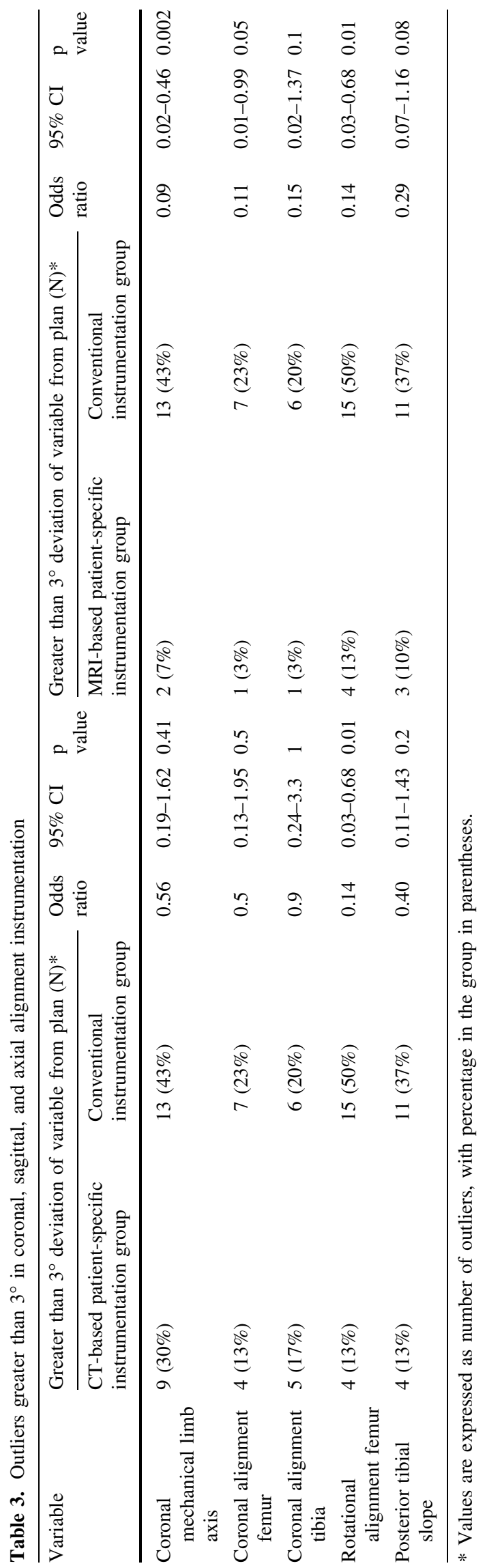

that patient-specific instrumentation should be widely used without additional investigation.

This study has limitations. Foremost, as no company currently manufactures CT- and MRI-based patient-specific instrumentation, TKA prostheses and their associated surgical instrumentations were used from two different manufacturers. As such, differences in findings may be biased by differences in the two manufacturer's designs, as opposed to patient-specific instrumentation techniques. Second, the followup is short at mean of 3 months. However, the goals of the study were to investigate immediate postoperative alignment and early postoperative outcome. Patient-specific instrumentation is advocated to be less invasive owing to the intact femoral medullary canal $[16,27]$. In the case of fast-track rehabilitation protocols early postoperative outcome might be of interest. However, no conclusions regarding long-term outcomes can be made with these data. Third, we did not complete interclass or intraclass reliability assessments in those who interpreted the postoperative long-leg radiographs. This is similar to another study [49]. However, the investigator (TP) who completed the measurements is an experienced knee surgeon who has performed more than 1000 TKAs and more than 500 postoperative radiologic alignment measurements in TKA. Finally, in consideration of the experience of the surgeon and because only small differences were found, the findings are not generalizable for daily practice of most knee surgeons.

In this investigation, we found that MRI- and CT-based patient-specific instrumentation were more accurate in comparison to conventional instrumentation in achieving the planned position in all three planes, although the differences were small. However, the rate of outliers greater than $3^{\circ}$ representing more clinical effect also was reduced in both patient-specific instrumentation groups in all three planes. Although this has been shown in several studies for coronal alignment [10, 15, 27], numerous studies have shown no difference in postoperative coronal alignment between patient-specific instrumentation and conventional instrumentation [2, 24, 26, 37, 49]. Less information is available regarding sagittal and rotational alignment [10, $18,38,46]$. Although the accuracy of achieving the planned rotation was similar between the MRI- and CT-based patient-specific instrumentation groups in our study, accuracy was improved for both patient-specific instrumentation approaches compared with the conventional instrumentation group. Similarly, Heyse and Tibesku [18] reported improved femoral component rotation with MRI-based patient-specific instrumentation, while Silva et al. [46] found improved tibial component rotation with MRI-based patient-specific instrumentation. However, Parratte et al. [39] found that postoperative rotation is not improved with the use of patient-specific instrumentation. In their 
Table 4. Coronal, sagittal, and axial alignment differences

\begin{tabular}{|c|c|c|c|c|c|c|}
\hline \multirow[t]{2}{*}{ Variable } & \multicolumn{2}{|c|}{ Deviation of variable from plan* } & \multirow[t]{2}{*}{$\mathrm{p}$ value } & \multicolumn{2}{|c|}{ Deviation of variable from plan* } & \multirow[t]{2}{*}{$\mathrm{p}$ value } \\
\hline & $\begin{array}{l}\text { CT-based patient- } \\
\text { specific instrumentation } \\
\text { group }\end{array}$ & $\begin{array}{l}\text { Conventional } \\
\text { instrumentation } \\
\text { group }\end{array}$ & & $\begin{array}{l}\text { MRI-based patient- } \\
\text { specific instrumentation } \\
\text { group }\end{array}$ & $\begin{array}{l}\text { Conventional } \\
\text { instrumentation } \\
\text { group }\end{array}$ & \\
\hline Coronal mechanical limb axis & $3.0^{\circ}\left(0^{\circ}-5^{\circ}\right)$ & $4.5^{\circ}\left(0^{\circ}-8^{\circ}\right)$ & 0.02 & $1.0^{\circ}\left(0^{\circ}-4^{\circ}\right)$ & $4.5^{\circ}\left(0^{\circ}-8^{\circ}\right)$ & $<0.001$ \\
\hline Mechanical axis of femur & $1.0^{\circ}\left(0^{\circ}-2.5^{\circ}\right)$ & $2.7^{\circ}\left(1^{\circ}-6^{\circ}\right)$ & $<0.001$ & $1.0^{\circ}\left(0^{\circ}-2.5^{\circ}\right)$ & $2.7^{\circ}\left(1^{\circ}-6^{\circ}\right)$ & $<0.001$ \\
\hline Mechanical axis of tibia & $1.0^{\circ}\left(0^{\circ}-2^{\circ}\right)$ & $3.0^{\circ}\left(1^{\circ}-6^{\circ}\right)$ & $<0.001$ & $1.0^{\circ}\left(0^{\circ}-1.5^{\circ}\right)$ & $3.0^{\circ}\left(1^{\circ}-6^{\circ}\right)$ & $<0.001$ \\
\hline Rotational alignment of femur & $1.0^{\circ}\left(0^{\circ}-2^{\circ}\right)$ & $4.0^{\circ}\left(1^{\circ}-7^{\circ}\right)$ & $<0.001$ & $1.0^{\circ}\left(0^{\circ}-2^{\circ}\right)$ & $4.0^{\circ}\left(1^{\circ}-7^{\circ}\right)$ & $<0.001$ \\
\hline Posterior tibial slope (from $3^{\circ}$ ) & $1.0^{\circ}\left(0^{\circ}-2^{\circ}\right)$ & $3.5^{\circ}\left(1^{\circ}-7^{\circ}\right)$ & $<0.001$ & $1.0^{\circ}\left(0^{\circ}-2^{\circ}\right)$ & $3.5^{\circ}\left(1^{\circ}-7^{\circ}\right)$ & $<0.001$ \\
\hline
\end{tabular}

* Values are expressed as median, with range in parentheses.

Table 5. Coronal, sagittal, and axial alignment differences between MRI and CT

\begin{tabular}{|c|c|c|c|}
\hline \multirow[t]{2}{*}{ Variable } & \multicolumn{2}{|c|}{ Deviation of variable from plan* } & \multirow[t]{2}{*}{$\mathrm{p}$ value } \\
\hline & $\begin{array}{l}\text { CT-based } \\
\text { patient- } \\
\text { specific } \\
\text { instrumentation } \\
\text { group }\end{array}$ & $\begin{array}{l}\text { MRI-based } \\
\text { patient- } \\
\text { specific } \\
\text { instrumentation } \\
\text { group }\end{array}$ & \\
\hline Long-leg mechanical axis & $3.0^{\circ}\left(0^{\circ}-5^{\circ}\right)$ & $1.0^{\circ}\left(0^{\circ}-4^{\circ}\right)$ & 0.03 \\
\hline Mechanical axis of femur & $1.0^{\circ}\left(0^{\circ}-2.5^{\circ}\right)$ & $1.0^{\circ}\left(0^{\circ}-2.5^{\circ}\right)$ & 0.18 \\
\hline Mechanical axis of tibia & $1.0^{\circ}\left(0^{\circ}-2^{\circ}\right)$ & $1.0^{\circ}\left(0^{\circ}-1.5^{\circ}\right)$ & 0.45 \\
\hline $\begin{array}{l}\text { Rotational alignment } \\
\text { of femur }\end{array}$ & $1.0^{\circ}\left(0^{\circ}-2^{\circ}\right)$ & $1.0^{\circ}\left(0^{\circ}-2^{\circ}\right)$ & 0.56 \\
\hline $\begin{array}{l}\text { Posterior tibial slope } \\
\quad\left(\text { from } 3^{\circ}\right)\end{array}$ & $1.0^{\circ}\left(0^{\circ}-2^{\circ}\right)$ & $1.0^{\circ}\left(0^{\circ}-2^{\circ}\right)$ & 0.60 \\
\hline
\end{tabular}

* Values are expressed as median, with range in parentheses.

randomized clinical trial, they found no improvement in postoperative rotation of femoral or tibial components when MRI-based patient-specific instrumentation was used. These inconsistent results may be caused by two major issues with patient-specific instrumentation. First, image rendering of the three-dimensional model is performed by every patient-specific instrumentation manufacturer in its specific way which may influence the accuracy and increase the differences depending on the used algorithm. Additionally, in most cases the planning is outsourced to an engineer and not performed by the surgeon, which also is a potential source of error. Second, precision of the device is highly dependent on intraoperative accuracy. For these reasons, the surgeon has to be very experienced and accurate in preparing the surfaces and soft tissues for the fit of the patient-specific instrumentation. Otherwise inaccuracies caused by the surgeon and not by the patient-specific instrumentation may occur [48]. Together with the small differences of the alignment measurements, these errors may substantially affect the results.
More uniquely, we found that MRI-based patient-specific instrumentation is more accurate than CT-based patient-specific instrumentation regarding the postoperative mechanical axis. However, differences were small and there were no differences in individual component coronal, sagittal, or rotational alignments. Accordingly, the rate of outliers greater than $3^{\circ}$ for mechanical limb alignment was reduced in the MRI group. To our knowledge, there is only one other study that has compared MRI- and CT-based patient-specific instrumentation [15]. In their randomized clinical trial, Ensini et al. [15] compared 25 MRI-based patient-specific instrumentation TKAs with 25 CT-based patient-specific instrumentation TKAs. They found no difference in coronal alignment but MRI-based patient-specific instrumentation was more accurate achieving the planned femoral sagittal position. However, in their study, only postoperative long-leg radiographs were obtained. As such, component rotation could not be analyzed. It is likely that the MRI-based technique provides improved imaging of the cartilage surfaces $[6,9,22,44,47]$. Based on the cartilage surface estimated by the surgeon with CT-based patient-specific instrumentation, deviations from the real joint surface are possible, which can result in a poorer fit. Looking at a more economic view point, costs for MRI were USD 438 compared with USD 253 for CT at our institution. Until there is no relevant clinical difference in outcome, this might affect decision making.

Additionally, individual femoral or tibial component alignment was not different between MRI-based and CTbased patient-specific instrumentation. In case of these small individual differences only summation of femoral and tibial deviation might show a significant difference between the groups. Another major issue of patient-specific instrumentation is that it does not take soft tissues into consideration during planning, with subsequent gap imbalance on postoperative standing radiographs.

Third, we found no differences in short-term clinical outcomes (Knee Society score or WOMAC score) among 
the three groups. There was distinct improvement in all patients after TKA, therefore differences between the groups are difficult to determine with our data. The lack of improvement in early clinical outcomes with patientspecific instrumentation is in accordance with other minimally invasive techniques combined with navigation [19, 28, 41]. Similar to our findings, Pietsch et al. [41] conducted a randomized clinical trial of 80 patients divided into conventional instrumentation and patient-specific instrumentation groups and found no difference in the Knee Society score at 3 months. This implies that the proposed less invasive use of patient-specific instrumentation does not show substantial benefits for patients and therefore should not be recommended in general.

This also raises the question if mechanical alignment outside $3^{\circ}$ influences function and survival. Although studies have shown no difference in outcome and survival with malalignment greater than $3^{\circ}[30,39]$, until there are more long-term studies a neutral mechanical axis remains the gold standard.

Finally, the duration of surgery in our study was reduced when using patient-specific instrumentation in comparison to conventional instrumentation. This is consistent with other studies which also found a reduction in duration of surgery, owing to more time-efficient positioning and sizing during surgery $[16,27,36,37,48]$. We also found a shorter duration of surgery in the MRI-based patient-specific instrumentation group compared with the CT-based patient-specific instrumentation group. To our knowledge, this was not investigated in previous studies. During surgery we found that appropriate placement of MRI-based patient-specific instrumentation took less time compared with CT-based patient-specific instrumentation. This might contribute to the shorter duration of surgery with MRIbased patient-specific instrumentation. Additionally the need to change the planned size intraoperatively was greater in the conventional group in comparison to both patient-specific instrumentation groups. This also might lengthen the duration of surgery, but differences were small and of questionable relevance.

Differences between patient-specific instrumentation and conventional instrumentation regarding alignment were statistically identifiable but small and therefore of questionable clinical importance. There were no differences in short-term clinical outcome and only a small decrease in the duration of surgery. Taking the unproven proposed benefits of patient-specific instrumentation, the increased costs and planning, and the risk associated with relatively new implants into consideration, patient-specific instrumentation should not be widely used.

Acknowledgments We thank Kai Wilke MD (Orthopedic Department, Hospital Märkisch Oderland, Section Wriezen, Wriezen,
Germany) for assistance with the study and randomization of the patients.

\section{References}

1. Ast MP, Nam D, Haas SB. Patient-specific instrumentation for total knee arthroplasty: a review. Orthop Clin North Am. 2012;43:e17-22.

2. Barrett W, Hoeffel D, Dalury D, Mason JB, Murphy J, Himden S. In-vivo alignment comparing patient specific instrumentation with both conventional and computer assisted surgery (CAS) instrumentation in total knee arthroplasty. J Arthroplasty. 2014;29:343-347.

3. Berger RA, Crossett LS, Jacobs JJ, Rubash HE. Malrotation causing patellofemoral complications after total knee arthroplasty. Clin Orthop Relat Res. 1998;356:144-153.

4. Bhattee G, Moonot P, Govindaswamy R, Pope A, Fiddian N, Harvey A. Does malrotation of components correlate with patient dissatisfaction following secondary patellar resurfacing? Knee. 2014;21:247-251.

5. Bombardier $\mathrm{CH}$, Buchwald D. Outcome and prognosis of patients with chronic fatigue vs chronic fatigue syndrome. Arch Intern Med. 1995;155:2105-2110.

6. Bousson V, Lowitz T, Laouisset L, Engelke K, Laredo JD. CT imaging for the investigation of subchondral bone in knee osteoarthritis. Osteoporos Int. 2012;23 (suppl 8):S861-865.

7. Brin YS, Nikolaou VS, Joseph L, Zukor DJ, Antoniou J. Imageless computer assisted versus conventional total knee replacement: a Bayesian meta-analysis of 23 comparative studies. Int Orthop. 2011;35:331-339.

8. Cenni F, Timoncini A, Ensini A, Tamarri S, Belvedere C, D’Angeli V, Giannini S, Leardini A. Three-dimensional implant position and orientation after total knee replacement performed with patient-specific instrumentation systems. J Orthop Res. 2014;32:331-337.

9. Chan WP, Lang P, Stevens MP, Sack K, Majumdar S, Stoller DW, Basch C, Genant HK. Osteoarthritis of the knee: comparison of radiography, CT, and MR imaging to assess extent and severity. AJR Am J Roentgenol. 1991;157:799-806.

10. Chen JY, Yeo SJ, Yew AK, Tay DK, Chia SL, Lo NN, Chin PL. The radiological outcomes of patient-specific instrumentation versus conventional total knee arthroplasty. Knee Surg Sports Traumatol Arthrosc. 2014; 22:630-635.

11. Cheng T, Zhang G, Zhang X. Imageless navigation system does not improve component rotational alignment in total knee arthroplasty. J Surg Res. 2011;171:590-600.

12. Cheng T, Zhao S, Peng X, Zhang X. Does computer-assisted surgery improve postoperative leg alignment and implant positioning following total knee arthroplasty? A meta-analysis of randomized controlled trials? Knee Surg Sports Traumatol Arthrosc. 2012;20:1307-1322.

13. Cooke TD, Scudamore RA, Bryant JT, Sorbie C, Siu D, Fisher B. A quantitative approach to radiography of the lower limb: principles and applications. J Bone Joint Surg Br. 1991;73:715-720.

14. Daniilidis K, Tibesku CO. Frontal plane alignment after total knee arthroplasty using patient-specific instruments. Int Orthop. 2013;37:45-50.

15. Ensini A, Timoncini A, Cenni F, Belvedere C, Fusai F, Leardini A, Giannini S. Intra- and post-operative accuracy assessments of two different patient-specific instrumentation systems for total knee replacement. Knee Surg Sports Traumatol Arthrosc. 2014; 22:621-629.

16. Hafez MA, Chelule KL, Seedhom BB, Sherman KP. Computerassisted total knee arthroplasty using patient-specific templating. Clin Orthop Relat Res. 2006;444:184-192. 
17. Han HS, Seong SC, Lee S, Lee MC. Rotational alignment of femoral components in total knee arthroplasty: nonimage-based navigation system versus conventional technique. Orthopedics. 2006;29(10 suppl):S148-151.

18. Heyse TJ, Tibesku CO. Improved femoral component rotation in TKA using patient-specific instrumentation. Knee. 2014;21: 268-271.

19. Howell SM, Hodapp EE, Kuznik K, Hull ML. In vivo adduction and reverse axial rotation (external) of the tibial component can be minimized. Orthopedics. 2009;32:319.

20. Hunt MA, Fowler PJ, Birmingham TB, Jenkyn TR, Giffin JR. Foot rotational effects on radiographic measures of lower limb alignment. Can J Surg. 2006;49:401-406.

21. Insall JN, Dorr LD, Scott RD, Scott WN. Rationale of the Knee Society clinical rating system. Clin Orthop Relat Res. 1989;248: $13-14$.

22. Kalke RJ, Di Primio GA, Schweitzer ME. MR and CT arthrography of the knee. Semin Musculoskelet Radiol. 2012;16:57-68.

23. Kamat YD, Aurakzai KM, Adhikari AR, Matthews D, Kalairajah Y, Field RE. Does computer navigation in total knee arthroplasty improve patient outcome at midterm follow-up? Int Orthop. 2009;33:1567-1570.

24. Koch PP, Muller D, Pisan M, Fucentese SF. Radiographic accuracy in TKA with a CT-based patient-specific cutting block technique. Knee Surg Sports Traumatol Arthrosc. 2013;21: 2200-2205.

25. Lombardi AV Jr, Berend KR, Ng VY. Neutral mechanical alignment: a requirement for successful TKA: affirms. Orthopedics. 2011;34:e504-506.

26. Lustig S, Scholes CJ, Oussedik SI, Kinzel V, Coolican MR, Parker DA. Unsatisfactory accuracy as determined by computer navigation of VISIONAIRE patient-specific instrumentation for total knee arthroplasty. J Arthroplasty. 2013;28:469-473.

27. MacDessi SJ, Jang B, Harris IA, Wheatley E, Bryant C, Chen DB. A comparison of alignment using patient specific guides, computer navigation and conventional instrumentation in total knee arthroplasty. Knee. 2014;21:406-409.

28. Martin A, Sheinkop MB, Langhenry MM, Widemschek M, Benesch T, von Strempel A. Comparison of two minimally invasive implantation instrument-sets for total knee arthroplasty. Knee Surg Sports Traumatol Arthrosc. 2010;18:359-366.

29. Matsuda S, Kawahara S, Okazaki K, Tashiro Y, Iwamoto Y. Postoperative alignment and ROM affect patient satisfaction after TKA. Clin Orthop Relat Res. 2013;471:127-133.

30. Matziolis G, Boenicke H, Pfiel S, Wassilew G, Perka C. The gap technique does not rotate the femur parallel to the epicondylar axis. Arch Orthop Trauma Surg. 2011;131:163-166.

31. Matziolis G, Pfitzner T, Thiele K, Matziolis D, Perka C. Influence of the position of the fibular head after implantation of a total knee prosthesis on femorotibial rotation. Orthopedics. 2011;34: e610-614.

32. Minoda Y, Kobayashi A, Iwaki H, Ohashi H, Takaoka K. TKA sagittal alignment with navigation systems and conventional techniques vary only a few degrees. Clin Orthop Relat Res. 2009;467:1000-1006.

33. Moher D, Hopewell S, Schulz KF, Montori V, Gotzsche PC, Devereaux PJ, Elbourne D, Egger M, Altman DG; Consolidated Standards of Reporting Trials Group. CONSORT 2010 explanation and elaboration: updated guidelines for reporting parallel group randomised trials. J Clin Epidemiol. 2010;63:e1-37.

34. Nam D, McArthur BA, Cross MB, Pearle AD, Mayman DJ, Haas SB. Patient-specific instrumentation in total knee arthroplasty: a review. J Knee Surg. 2012;25:213-219.
35. Ng VY, DeClaire JH, Berend KR, Gulick BC, Lombardi AV Jr. Improved accuracy of alignment with patient-specific positioning guides compared with manual instrumentation in TKA. Clin Orthop Relat Res. 2012;470:99-107.

36. Noble JW Jr, Moore CA, Liu N. The value of patient-matched instrumentation in total knee arthroplasty. $J$ Arthroplasty. 2012;27:153-155

37. Nunley RM, Ellison BS, Zhu J, Ruh EL, Howell SM, Barrack RL. Do patient-specific guides improve coronal alignment in total knee arthroplasty? Clin Orthop Relat Res. 2012;470:895-902.

38. Parratte S, Blanc G, Boussemart T, Ollivier M, Le Corroller T, Argenson JN. Rotation in total knee arthroplasty: no difference between patient-specific and conventional instrumentation. Knee Surg Sports Traumatol Arthrosc. 2013;21:2213-2219.

39. Parratte S, Pagnano MW, Trousdale RT, Berry DJ. Effect of postoperative mechanical axis alignment on the fifteen-year survival of modern, cemented total knee replacements. J Bone Joint Surg Am. 2010;92:2143-2149.

40. Pfitzner T, Rohner E, Preininger B, Perka C, Matziolis G. Femur positioning in navigated total knee arthroplasty. Orthopedics. 2012;35(10 suppl):45-49.

41. Pietsch M, Djahani O, Hochegger M, Plattner F, Hofmann S. Patient-specific total knee arthroplasty: the importance of planning by the surgeon. Knee Surg Sports Traumatol Arthrosc. 2013;21:2220-2226.

42. Pietsch M, Hofmann S. [Value of radiographic examination of the knee joint for the orthopedic surgeon][in German]. Radiologe. 2006;46:55-64.

43. Ritter MA, Faris PM, Keating EM, Meding JB. Postoperative alignment of total knee replacement: its effect on survival. Clin Orthop Relat Res. 1994;299:153-156.

44. Roemer FW, Crema MD, Trattnig S, Guermazi A. Advances in imaging of osteoarthritis and cartilage. Radiology. 2011;260: 332-354.

45. Shah DA, Madden LV. Nonparametric analysis of ordinal data in designed factorial experiments. Phytopathology. 2004;94:33-43.

46. Silva A, Sampaio R, Pinto E. Patient-specific instrumentation improves tibial component rotation in TKA. Knee Surg Sports Traumatol Arthrosc. 2014;22:636-642.

47. Smith TO, Drew BT, Toms AP, Donell ST, Hing CB. Accuracy of magnetic resonance imaging, magnetic resonance arthrography and computed tomography for the detection of chondral lesions of the knee. Knee Surg Sports Traumatol Arthrosc. 2012;20: 2367-2379.

48. Tibesku CO, Hofer P, Portegies W, Ruys CJ, Fennema P. Benefits of using customized instrumentation in total knee arthroplasty: results from an activity-based costing model. Arch Orthop Trauma Surg. 2013;133:405-411.

49. Victor J, Dujardin J, Vandenneucker H, Arnout N, Bellemans J. Patient-specific guides do not improve accuracy in total knee arthroplasty: a prospective randomized controlled trial. Clin $\mathrm{Or}$ thop Relat Res. 2014;472:263-271.

50. Watters TS, Mather RC 3rd, Browne JA, Berend KR, Lombardi AV Jr, Bolognesi MP. Analysis of procedure-related costs and proposed benefits of using patient-specific approach in total knee arthroplasty. J Surg Orthop Adv. 2011;20:112-116.

51. Windsor RE, Scuderi GR, Moran MC, Insall JN. Mechanisms of failure of the femoral and tibial components in total knee arthroplasty. Clin Orthop Relat Res. 1989;248:15-19; discussion 19-20.

52. Yaffe MA, Koo SS, Stulberg SD. Radiographic and navigation measurements of TKA limb alignment do not correlate. Clin Orthop Relat Res. 2008;466:2736-2744. 